\title{
Nephrogenic syndrome of inappropriate antidiuresis
}

INSERM

\section{Source}

INSERM. (1999). Orphanet: an online rare disease and orphan drug data base.

Nephrogenic syndrome of inappropriate antidiuresis. ORPHA:93606

Nephrogenic syndrome of inappropriate antidiuresis (NSIAD) is a rare genetic disorder of water balance, closely resembling the far more frequent syndrome of inappropriate antidiuretic secretion (SIAD), and characterized by euvolemic hypotonic hyponatremia due to impaired free water excretion and undetectable or low plasma arg inine vasopressin (AVP) levels. 